\title{
Editorial Note on: Glucose tolerance and physical activity level in people with spinal cord injury
}

Spinal Cord (2010) 48, 597; doi:10.1038/sc.2010.31; published online 23 March 2010

Editorial Note on: Spinal Cord (2010) 48, 591-596; doi:10.1038/sc.2009.180; published online 5 January 2010

The paper by Raymond et al. ${ }^{1}$ is interesting and the results are of import to the spinal cord community; however, there is concern regarding the validity of using a retrospective questionnaire rather than objectively measuring the physical capacity or asking the subjects to keep a daily activity log. The paper referenced ${ }^{2}$ suggests good preliminary construct validity in a sample of 372 subjects with disabilities, of which only $31 \%$ were individuals with SCI. Similar glucose levels among highly trained compared with sedentary individuals with SCI have been reported, suggesting that glucose metabolism is not related to activity status in this population; however, physical activity was not measured objectively. ${ }^{3}$ A future endeavor to examine the effects of actual activity, measured with an accelerometer or the like, in combination with a daily activity log on the findings of glucose metabolism in this population would be of value. Although the introduction of measurements of daily activity (using an accelerometer and the daily activity log) may present a bias, individual perceptions of level of activity may vary, which will also bias the data sample. In addition, the concept of redundancy between neurological level and completeness of the spinal lesion and level of physical activity is not novel. ${ }^{4}$ Confirmation of the findings reported herein through actual measurements would be a useful addition to the literature. The unanswered question remains: can we document improved glucose metabolism after a period of exercise training in the SCI population?

\section{Conflict of interest}

The author declares no conflict of interest.

JM Wecht

VA Medical Center, Bronx, NY, USA E-mail: JM.Wecht@va.gov

\section{References}

1 Raymond J, Harmer AR, Temesi J, van Kemenade C. Glucose tolerance and physical activity level in people with spinal cord injury. Spinal Cord 2010; 48: 591-596.

2 Washburn RA, Zhu W, McAuley E, Frogley M, Figoni SF. The physical activity scale for individuals with physical disabilities: development and evaluation. Arch Phys Med Rehabil 2002; 83: 193-200.

3 Dearwater SR, LaPorte RE, Robertson RJ, Brenes G, Adams LL, Becker D. Activity in the spinal cord-injured patient: an epidemiologic analysis of metabolic parameters. Med Sci Sports Exerc 1986; 18: 541-544.

4 Bauman WA, Adkins RH, Spungen AM, Waters RL. The effect of residual neurological deficit on oral glucose tolerance in persons with chronic spinal cord injury. Spinal Cord 1999; 37: 765-771. 